University at Buffalo School of Law

Digital Commons @ University at Buffalo School of Law

$12-27-2019$

\title{
Governance Interactions in Sustainable Supply Chain \\ Management
}

\author{
Errol Meidinger \\ University at Buffalo School of Law, eemeid@buffalo.edu
}

Follow this and additional works at: https://digitalcommons.law.buffalo.edu/book_sections

Part of the International Relations Commons, and the International Trade Law Commons

\author{
Recommended Citation \\ Meidinger, Errol, "Governance Interactions in Sustainable Supply Chain Management" (2019). \\ Contributions to Books. 377. \\ https://digitalcommons.law.buffalo.edu/book_sections/377
}

This is a draft chapter. The final version is available in Transnational Business Governance Interactions: Enhancing Regulatory Capacity, Ratcheting up Standards, and Empowering Marginalized Actors edited by Stepan Wood, Rebecca Schmidt, Errol Meidinger,Burkard Eberlein, and Kenneth W. Abbot, published in 2019, Edward Elgar Publishing Ltd. https://doi.org/10.4337/9781788114738.00011. The material cannot be used for any other purpose without further permission of the publisher, and is for private use only.

\section{IN COPYRIGHT}

This Book is brought to you for free and open access by the Faculty Scholarship at Digital Commons @ University at Buffalo School of Law. It has been accepted for inclusion in Contributions to Books by an authorized administrator of Digital Commons @ University at Buffalo School of Law. For more information, please contact lawscholar@buffalo.edu. 


\title{
Governance Interactions in Sustainable Supply Chain Management*
}

\author{
Errol Meidinger \\ University at Buffalo School of Law \\ The State University of New York \\ eemeid@buffalo.edu
}

\begin{abstract}
"Supply chains" are a major site of transnational business governance, and yet their dynamics and effectiveness are usually more assumed than interrogated in regulatory governance discourse. The very term "chain" implies a more determinist and simplistic understanding of supply relationships than is empirically supportable. Supply chains in practice are complex, dynamic, and highly variable networks. Based on peer-group presentations by over 60 supply chain professionals, this paper analyzes sustainable supply chain management practices in terms of the interactions conceptions of the Transnational Business Governance Interactions framework. It discusses possible refinements of the framework and suggests that sustainable supply chain management (1) is likely to make modest contributions to improving governance capacity, (2) may or may not ratchet up standards, and (3) may help protect marginalized parties, but is focused on better using the existing power of lead firms in supply chains.
\end{abstract}

\section{Key Words}

Auditing, corporate social responsibility, environment, governance, human rights, management system, supply chain, supply network, sustainability, sustainable supply chain management, value chain

\section{Introduction}

Transnational governance initiatives seeking to advance environmental protection, community development, human rights, labor conditions, and other "sustainability" goals are increasingly focusing on supply chain management. So much so, that "sustainable supply chain management" (SSCM) has become a category of practice and can be seen as a movement of sorts, one that includes corporate managers, consultants, labor and environmental activists, and academics, among

\footnotetext{
* Article under preparation for the forthcoming volume, Transnational Business Governance Interactions: Enhancing Regulatory Capacity, Ratcheting up Standards and Empowering Marginalized Actors, Stepan Wood, Rebecca Schmidt, Errol Meidinger, Burkard Eberlein, and Kenneth Abbott, editors. Edward Elgar Publishers. Helpful comments by Matthew Bach, Guyora Binder, Todd Brown, Abigail Cooke, Matt Dimick, James Gardner, Jennifer Hunt, Meredith Lewis, Tara Melish, Jessica Owley, Christine Parker, John Henry Schlegel, Margaret Shannon, Mateo Taussig-Rubbo, David Westbrook, and my co-editors are gratefully acknowledged, as is research funding provided by the Baldy Center for Law \& Social Policy, The State University of New York at Buffalo.
} 
others. Like many such categories composed of disparate elements, SSCM has no single definition (e.g., Seuring and Müller 2008) ${ }^{1}$. But a central feature is that activists private and public, for- and not-for-profit - seek to enlist the supply chain management capacities of businesses to pursue public purposes. Doing so requires sustained effort to restructure supply chain management goals and relationships. That restructuring is a matter of relatively public dialogue, debate, management activity, and experimentation. Because the patterns of interaction involved are not yet settled into taken-for-granted organizational routines, the sustainable supply chain movement provides an illuminating window into an important field of emerging transnational governance interactions.

This paper uses the Transnational Business Governance Interactions (TBGI) framework (Eberlein et al 2014) to analyze the interactive strategies and relationships promoted by SSCM professionals. It aims to offer a new perspective on SSCM interactions and to add to the pool of empirical information in the TBGI discussion. The paper also critically discusses the usefulness of the TBGI framework for understanding this kind of transnational governance activity, as well as its limitations and possible adjustments. Finally, it offers some reflections on the potential of SSCM to enhance governance processes and concludes that, while SSCM is likely to enhance overall pursuit of social welfare goals in many contexts, it may or may not significantly ratchet up social and environmental standards. Moreover, while SSCM does offer increased protection of marginalized interests, it focuses on harnessing the existing power of lead firms in supply chains, rather than on empowering weaker interests.

The paper proceeds as follows. The next few sub-sections discuss, respectively, data and research method, the TBGI framework, the key axioms of supply chain management as a discipline, the growth of "sustainable" supply chain management, and the role of corporate management systems in the SSCM movement. The subsequent, primary section summarizes and analyzes public presentations and comments by SSCM professionals in terms of the TBGI framework. It seeks to characterize the types of interactions common in supply chains, as described by as those professionals who see and work with them. It also summarizes what they see as the primary challenges and potential solutions for achieving sustainable supply chains. The concluding section considers the implications of those diagnoses and prescriptions for the TBGI framework generally, and also for the goals of improving governance, ratcheting up environmental and social standards, and empowering marginalized interests.

\section{Data and Method}

The data used for this paper are drawn from public presentations and comments of approximately 6o SSCM professionals at two "sustainable supply chain summits"

\footnotetext{
1 Seuring and Müller define SSCM as "the management of material, information and capital flows as well as cooperation among companies along the supply chain while taking goals from all three dimensions of sustainable development, i.e., economic, environmental, and social, into account which are derived from customer and stakeholder requirements." There are many other definitions, but this one serves to illustrate the difficulty of encapsulating the congeries of practices and concerns bundled into SSCM.
} 
organized by The Ethical Corporation in London in 2014 and 2015. Presenters included corporate procurement officials directly involved in supply chain management, a variety of supply chain consultants, facilitators, and contractors, and NGO staffers active in SSCM initiatives. The conferences were cast as opportunities to meet with large numbers of "senior-level executives ... for ... high level business discussions for CSR (corporate social responsibility), sustainability, supply chain, and procurement professionals," and as opportunities to get the most up-to-date information from leaders in the field regarding how to achieve such goals as embedding sustainability, minimizing environmental footprint, increasing supply chain resilience, elevating monitoring systems and standards, developing suppliers effectively, bringing successful innovation to a corporate level, eliminating dependency on unsustainable raw materials, and moving toward a circular economy.

The approximately 150 attendees at each conference included a wide variety of professionals active in supply chain management. I was one of only two identifiable academics at the first conference, and apparently the only one at the second. The conferences were framed as business propositions where valuable information could be obtained and shared, thereby increasing supply chain value. They were relatively expensive to attend, with substantial fees for corporate attendees and nontrivial ones for NGOs and academics. The price seemed worth paying for the opportunity to hear narratives, recommendations, and discussion from such a large number of SSCM practitioners - and indeed it turned out to be so. An advantage of the conference context was that it constrained speakers to make statements plausible and intelligible to their peers, a condition often not present in one-on-one interviews (Becker 1970). It also provided access to a much larger number and variety of practitioners than would have been possible through individually arranged interviews.

Although the presentations were public (for a price), the overall feeling of the conferences was one of a discussion among members of a professional community, which, although made up of individuals from different kinds of organizations, felt a shared interest in promoting supply chain sustainability. While there was a certain amount of competition and jockeying for position or recognition, I found the overall atmosphere to be relatively open and relaxed. Given that the primary purpose of this paper is to describe and analyze patterns of discourse and practice in a professional community, rather than the positions of specific individuals or companies, I have chosen to use field note numbers to identify the presenters and participants whose comments are discussed unless they directly reference a specific company or individual.

\section{The Transnational Business Governance Interactions Framework}

The TBGI framework posits that an important key to understanding transnational governance is to describe and analyze patterns of interaction among the many diverse actors that constitute transnational governance in the current era (Eberlein et al 2014). This is a necessary step to visualizing broad patterns in the rapidly emerging and changing transnational governance structures that we see unfolding. To help sort out the "blooming buzzing confusion," the framework seeks to organize interactions in terms of six generic kinds of tasks usually involved in governance: (1) 
framing the governance agenda and setting goals for it ("agenda setting"); (2) formulating norms and rules to be followed by those engaged in the activity of concern ("norm formation"); (3) implementing applicable goals, standards, and rules by those engaged in the activity ("implementation"); (4) gathering information on the state of the problem and monitoring the behavior at issue ("monitoring"); (5) responding to non-compliance via sanctions and other forms of enforcement activities ("enforcement"); and (6) evaluating governance operations and providing feedback for possible improvement ("evaluation" - thus the combined acronym "ANIMEE"). The framework assumes interplay and overlap among these tasks, and, importantly, does not assume that they occur in a set sequence. Supply chain management is usually thought of in terms of implementation and monitoring; but as discussed below, it can also involve significant elements of the other four types of governance tasks.

"Interactions" in the TBGI schema can occur among quite different types of actors, ranging from individuals, to organizations, to governance "schemes," to institutions, to larger economic or discursive structures. While the concrete nature of interactions can thus be almost infinitely variable, the TBGI framework offers four general categories for patterns of interaction: competition, coordination, cooptation (hierarchy), and chaos. In SSCM discourse the actors of interest are primarily organizations, although primary producers in some supply chains can be individuals. The presumptive patterns of interaction in supply chains are hierarchy and coordination, but some emerging forms tend to be complex mixtures of the two, with a little competition thrown in as well.

\section{Supply Chain Management}

Modern supply chain management built upon the relatively prosaic field of "logistics," which sought to integrate all of an individual firm's production activities to achieve maximum productive efficiency (Kent and Flint 1977). By the mid-1980s, economic globalization and the explosive growth of outsourcing had spawned the field of "supply chain management" to manage production chains involving multiple firms, and essentially to manage the supply chain as a single entity (Martin 2011), still with the goal of maximizing efficiency. Three concepts from the supply chain literature are important here: (1) the idea of the "value chain;" (2) modeling the chain as network; and (3) understanding supply chain coordination by a "lead firm."

Value Chain Models. When a supply chain is rendered as a list of necessary tasks in producing a product, each of which should efficiently contribute to the overall value of the product, it follows fairly easily to think of each task in terms of its "value added." Each task is expected to justify itself by producing net value to the enterprise (Porter 1985). Any activity for which a producing firm does not enjoy comparative advantage is a candidate for outsourcing to a firm that can provide a cost or value advantage, and outsourcing is thus a possibility for every activity in the process.

Perhaps ironically, value chain analysis also provides a basis for normative critique. Once a quantified value is allocated to each task in the production process, it is possible to critically analyze the allocation of rewards. This has given rise to a branch of 
value chain analysis concerned with "upgrading" - i.e., directing a larger share of the value produced to under-rewarded supply chain participants - often primary producers in developing countries. This can include "economic" (more resources), "social" (better treatment of workers and communities) (Gereffi 2011), and environmental upgrading (Marchi 2013).

Network Models. While outsourcing has often been portrayed as a movement from "hierarchy" (integration in a single firm) to "markets" (coordination through armslength inter-firm transactions), it is apparent that a great many interfirm supply chain relationships do not fit the arms-length model, but instead involve various kinds of ongoing relationships. Figure 1 's schematic model of a poultry supply chain shows transactional relationships running from farmers through a processor, distributors, and retailers (Van der Vorst, et al 2007). The question for supply chain management is how those transactions are coordinated. While they could be simple market transactions based entirely on price and quantity, the importance of food quality and safety for all members of the chain suggests that the parties along the chain will want to be confident that standards are maintained, and that they will prefer to work with partners they consider reliable.

Gereffi and colleagues (e.g., Gereffi and Lee 2012) have developed three ideal types of supply network relationships:

- Modular governance for cases in which suppliers make products to a customer's specifications that are complex but relatively easy to codify. This type of coordination often relies heavily on standards.

- Relational governance for cases when buyers and suppliers rely on complex information that is not easily conveyed or readily understood. These situations call for frequent interactions and knowledge sharing based on mutual trust and social ties between the parties.

- Captive governance typically involves a group of small suppliers who are dependent on one or a few buyers for resources and market access. Suppliers tend operate under conditions determined by, and often specific to, individual buyers.

These ideal types identify key aspects of the prescriptions of SSCM practitioners discussed in the next section. In addition, Figure 1 (van der Vorst, et al 2007) suggests several other important features of modern supply chains. First, supply chain relationships need not be limited to linking actors in one tier and the next. There is nothing to preclude horizontal relationships within a tier (although competition law may constrain them to certain forms). A supply chain manager for the British Food Retailer Tesco described the outsourced corporation as "a long stringy chain for each thing it produces - more like a net. . When Tesco gets a kicking for horsemeat, all of the supermarkets get it" (1413), thus indicating a shared interest in food quality that could foster concerted action with other retailers. 


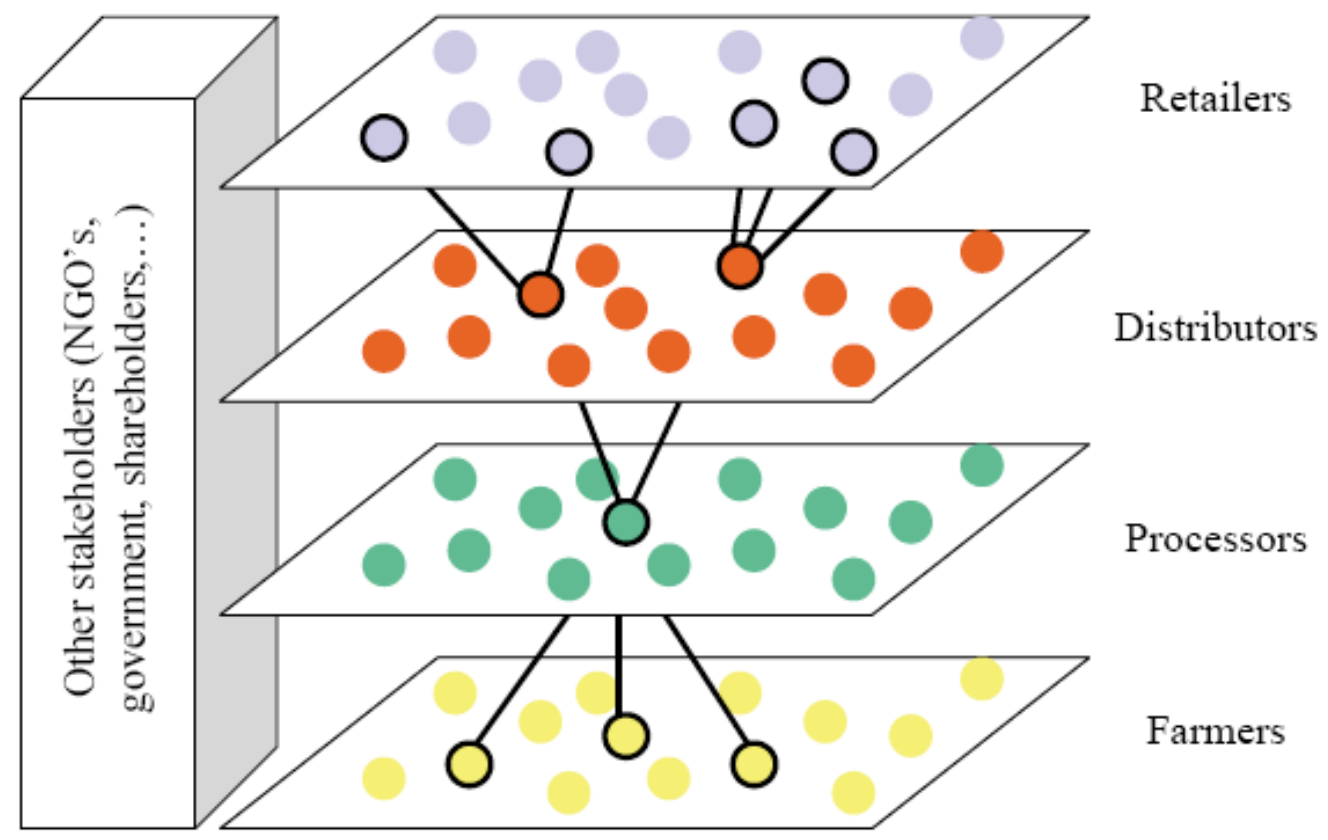

Figure 1. Typified Food Supply Chain

Nor is there any inherent reason that relationships cannot jump tiers; indeed, they often do. (Note for future reference that numbered tiers are widely used as shorthand in the supply chain world. Thus, from the perspective of retailers in this diagram, farmers would be "tier 3" suppliers.) It follows that groups of actors spanning the various levels can create networked alliances wherein they cooperate and trade regularly among themselves, while competing with other networked alliances, as also often happens. At the same time, any given member of a supply chain may also be involved in other supply chains. Thus, depending on the sector and nature of the supply chain, some actors may be parts of multiple supply chain networks, and subject to multiple, potentially conflicting pressures from different customers.

Finally, as indicated by the rectangular column on the left side of Figure 1, the extended supply network can involve actors who are not engaged in the making or handling of the product. These can include government regulators, civil society organizations, shareholders, researchers, interested members of the public, and others. Indeed, actors can potentially inject themselves into supply chain networks if they can affect the value of any of the activities carried out by participants. Researchers, for example, might increase or decrease the value of a given activity by developing a new technology or procedure. NGOs might affect it by influencing consumer or public opinion regarding its desirable or undesirable effects.

Lead Firm Coordination. Where a supply network is extensive and complex, a distinctive coordination role will often be needed. Conventionally, the most economically powerful actor in the supply network - frequently a major retailer like 
Walmart, Tesco, or Home Depot, or a valuable brand merchandizer like Nike or Liz Claiborne - plays this role. This "lead firm" exercises power over suppliers by setting terms of participation in the chain, often through "private standards" (Gereffi and Lee 2012). Such standards can expand to cover public welfare criteria such as workplace conditions and environmental practices, not merely characteristics of the product per se, and perhaps create incentives for "relational" governance in terms of the above typology.

\section{Sustainable Supply Chain Management}

Adding public welfare goals to the traditional "economic" ones of price and functionality greatly increases the challenges of supply chain management. The goals cited by the SSCM presenters discussed in this article cover an almost dizzying array, ranging from broadly environmental ones (air quality, energy conservation, water quality, water conservation, waste minimization, ecosystem service protection, land protection, etc.) to broadly social ones (community development, female empowerment, human rights, labor rights, anti-trafficking, worker health and safety, worker empowerment, anti-corruption, security, legality, improved consumer values, poverty reduction, etc.) Of course, many of these goals overlap, and SSCM is often used to encompass all of them. Nonetheless, their range is great, and the strategies for achieving them may be correspondingly diverse. Moreover, they may somewhat be at odds, involving normative choices for SSCM actors, as discussed in the 'agenda setting' and 'norm formation' sections below.

The core strategy of SSCM advocates calls for powerful businesses to incorporate environmental and social goals into their supply chain management procedures. While they could in principle do so on their own motion and in their own way, firms' policies are often shaped by broader, industry-wide standards programs such as the Forest Stewardship Council and Fairtrade International (Meidinger 2008), or even all-inclusive programs such as the UN Global Compact and the UN General Principles on Business and Human Rights (Leipziger 2017). Despite the formally voluntary nature of these programs, firms sometimes view them as de facto mandatory, since NGOs, civil society organizations, shareholder movements, and others pressure them to commit or risk significant brand damage.

De jure mandatory requirements are also emerging (Reid 2016). Examples include the US Dodd-Frank Act of 2010 (requiring publicly traded companies to issue reports on the possible use of conflict minerals in their supply chains); UK Modern Slavery Act of 2015 (requiring covered firms to prepare annual statements describing their policies, due diligence provisions, supply chain risks, measures, and effectiveness in countering human trafficking); and French Duty of Vigilance Law of 2017 (requiring firms to implement due diligence plans to protect against human rights and environmental risks in activities they control and in sub-contractors and suppliers on whom they have significant influence). According to one of the presenters (1422), Danish law requires the 1000 largest Danish companies to report annually on their CSR work and provides that the government will take and investigate complaints or questions from anywhere in a Danish company's supply chain. 
Corporate Management Systems. The programs mentioned above rely centrally on corporate management systems. The idea is that the corporation creates a structured operating system that (1) assesses the real or potential impacts of its activities on the concerns at issue, (2) develops a plan for managing those impacts, (3) monitors actual effects, and (4) assesses its degree of success and makes adjustments to improve its performance. Specific officials are designated to carry out the various tasks, and the organization achieves "continuous improvement" through a reiterated evaluation and adjustment process.

An idea-typical example of the corporate management system approach to sustainability governance is the due diligence mandate laid out in the 2011 UN Guiding Principles for Business and Human Rights (UNGPs). While states remain primarily responsible for "protecting" human rights, businesses are to "respect" human rights by (a) taking adequate measures to "avoid causing or contributing to adverse human rights impacts through their own activities, and addressing such impacts where they occur" and (b) "seek[ing] to prevent or mitigate adverse human rights impacts directly linked to their operations, products or services by their business relationships, even if they have not contributed to those impacts" (UNGPs \13). Activities are defined to include both acts and omissions, thus extending responsibility to possible failure to prevent negative effects.

While the supply chain responsibility in clause (b) is not very clearly defined, and seems to assume context-specific elucidation, it clearly extends duties to cover the behavior of supply chain partners. The corporation is to have an official, publicized, policy statement of human rights promulgated by senior management and communicated to all linked parties, including business partners as well as states, shareholders, and potentially affected persons. It is to operationalize the policy though a human rights due diligence process that includes "assessing actual and potential human rights impacts, integrating and acting upon the findings, tracking responses, and communicating how impacts are addressed" (UNGPs $\ 17$ ) ... in other words, a human rights management system.

The UNGPs envision that human rights due diligence will be incorporated into broader corporate risk management processes, with the proviso that the analysis must go beyond risks to the corporation itself to include risks to affected rights holders. They acknowledge that corporations with particularly large or complex supply chains may need to focus their attention on higher risk portions, rather than analyzing their entire chains (UNGPs \19). They also acknowledge that appropriate actions regarding behavior by other actors in their supply chains are likely to vary with the "extent of [the corporation's] leverage" (UNGPs \19) and the nature of the problem. Risk assessments also are to include "meaningful consultation with potentially affected groups" (UNGPs I 18). A growing number of companies issue annual corporate responsibility reports, and most of them also have publicly available sustainable sourcing codes for suppliers. 
However, relatively few report on the level of supplier compliance, much less which suppliers have been particularly problematic or what the company has done about it. ${ }^{2}$

\section{Interactions in Sustainable Supply Chain Governance}

This section analyzes public presentations by, and follow-up conversations with, approximately 60 SSCM professionals. Perhaps three-quarters worked in supply chain management for "lead firms;" the remainder held a variety of advocacy or consulting roles. The analysis is organized in terms of the ANIMEE categories discussed above. While this organization is somewhat artificial in that few activities fall cleanly in one category or another, it is nevertheless helpful in focusing separately the different kinds of interactions involved in SSCM.

\section{Agenda Setting}

The agenda for SSCM seems to come from nearly everywhere. Major sources include labor and human rights movements dating to the 1940s; the modern corporate responsibility movement dating back to the 1950s; the sustainable development movement dating to the 1970 , and the explosive proliferation of social and environmental certification programs that began in the late 1980 s and early $1990 \mathrm{~s}$. As noted above, the SSCM agenda now contains many goals ranging across community, environment, health and safety, human rights, governance, and labor.

Thus, businesses engaging in SSCM might seem to be passive receivers of a broad and largely preformed agenda. Yet, they still play important formative roles, because they have considerable latitude in deciding which goals to pursue and to what extent. Two striking themes came up regarding lead firm agendas for SSCM. The first was the articulation of a dynamic supply chain management agenda, which, in the framing of one presenter, involves a progression from compliance to environmental stewardship to value chain engagement to sustainable innovation (1502). Thus, the image of the supplier-customer relationship goes from one of control and predictability to one of interaction and innovation. This was a common theme among the SSCM professionals, who seem to be increasingly accepting the idea that a core part of the goal is to build relationships and supplier capacity, particularly in the less developed levels of the supply chain, and thereby to increase its dynamism and responsiveness.

Second, some SSCM managers espouse the goal of using their methodologies to change not only supplier behavior, but also consumer behavior. For example, some telephone companies develop eco-ratings of their handsets with the express hope of influencing retail customers to prefer ecologically superior phones, despite the apparent low consumer demand for such phones (1505). This is a potentially significant effort to create, rather than simply respond to, sustainability values.

\footnotetext{
${ }^{2}$ This observation is based on several types of sources, including studies of CSR reports from approximately 30 prominent companies by students in my International Business Transactions course, frequent comments by practitioners, and reports such as Langlois (2017), which assesses 74 of the world's largest companies.
} 
External activists also significantly shape SSCM agendas. Former managers for US-based computer companies described how demonstrations by activists outside a Hewlett-Packard manufacturing facility in Oregon suddenly put the rare metal, tantalum, on their agenda when it would not otherwise have been $(1416,1432)$. Their companies used relatively little of the metal, and their supplies came from several parts of the world, not just Democratic Republic of Congo, where revenues from its sale were believed to be fueling armed conflict. However, the demonstrations put it on their agendas in a powerful way, leading ultimately to computer companies establishing a new conflict-free smelter audit program, which is now subscribed to by many leading actors in the computer industry. There are also many less dramatic examples of activists shaping the SSCM agenda, such as the Ethical Trading Initiative described in the next sub-section.

\section{Norm Formation}

Norm formation merges and mingles with agenda setting. Indeed, agenda setting sometimes proceeds through actors promulgating and asserting standards to be followed in a particular governance arena, as was the case with forest certification (Meidinger 2006). Such initiatives typically draw on a broad existing body of received standards, goals, and maxims generated in variety of arenas, including intergovernmental forums. In the SSCM arena, a large number of standards take the form of supplier codes of conduct or supplier responsibility standards. There could conceivably be as many different standards as purchasing firms, since the firms write the contracts specifying supplier performance. In practice codes of conduct have long tended to be similar within industry groups, often organized along national lines (Jenkins 2001). Industry-developed codes of conduct have sometimes provoked counter codes developed by NGOs or multi-stakeholder groups. The Ethical Trading Initiative (ETI), for example, was founded by a group of UK companies, NGOs, and trade unions to establish what they saw as a more credible standard for protecting worker rights worldwide than could be produced by corporations themselves (ETI 2018a). The ETI 'base code' consists of nine standards that all member companies (currently over eighty) must adopt (ETI 2018b). The ETI actively promotes the standard and participates in dialogues regarding implementation, including having one of its staff members make the presentation discussed in this paper.

Although it is impossible to tally all sustainable supply chain codes, the International Trade Center currently lists 238 standards, codes, and protocols in its Standards Map, which is intended to help companies find standards that might apply to them (ITC 2018). This number grew by more than twenty in 2017. SSCM experts appear to strongly agree that there are too many standards in use and that some sort of harmonization or unification is necessary. One speaker stressed the need for a "super aligner" to harmonize all of the standards (1403). The main reasons for this view, discussed further below, are practical. If codes are highly variable they can be unnecessarily costly for suppliers to comply with, since multiple codes often apply to any given operation. They will probably also be more difficult for consumers to understand or trust. 
New standards are continuously being developed, in some cases to harmonize requirements within industries and in others simply to create relevant or workable standards for an otherwise uncovered type of supply chain. An example of the first is a collaborative standard setting process by the chemicals industry: "Together for Sustainability"[TfS], founded in 2011 by the chief procurement officers of six multinational chemical companies. Its purpose "is to develop and implement a global audit program to assess and improve sustainability practices within the supply chains of the chemical industry" (TfS 2018). Development of the standard involved little direct participation by non-industry actors. Instead, it is based on the UN Global Compact, which did involve significant participation by non-industry actors, and Responsible Care, the chemical industry's preexisting code of conduct, where non-industry participation was limited and came relatively late (TfS url). The TfS process seems to have relied heavily on strong relationships with the Ethical Corporation, which recently gave it a prize, and with Ecovadis, which describes itself as a "collaborative platform providing Supplier Sustainability Ratings for global supply chains" (Ecovadis 2018). Thus, the interaction pattern here appears to be between a powerful, industry-specific group (TfS), a general supply chain sustainability rater (Ecovadis), and a "business intelligence company for sustainability" (Ethical Corporation). Each is primarily business oriented, and yet they seem confident of their ability to promulgate, evaluate, publicize, and legitimate SSCM standards.

An example of a standard developed for an apparently previously uncovered supply chain is the "Bettercoal Code," which was developed by a group of major coal buyers "to promote the continuous improvement of sustainability performance in their coal supply chain," specifically mining operations (Bettercoal 2018). It was prepared by European coal buyers and facilitated by Business for Social Responsibility (BSR). BSR is a non-profit organization that seeks to "catalyze change within business by integrating sustainability into strategy and operations, and to promote collaboration among companies and their stakeholders for systemic progress toward a just and sustainable world" (BSR 2018). Like TfS, the Bettercoal Code is also built from existing standards, including International Finance Corporation investment standards, International Labor Organization labor standards, and UNGPs (1414).

Interestingly, the producers of the Bettercoal Code are quite aware and public regarding potential antitrust law concerns posed by their collaboration in setting purchasing standards, and posted an antitrust policy directly on their website. The policy prohibits communications or agreements regarding banned subjects, including prices, pricing policies, terms of sale, customer lists, production costs, marketing plans, and the like (Bettercoal url). Antitrust concerns regarding standard setting as well as other forms of industry collaboration are widespread. Collaboration is nonetheless occurring in many arenas of SSCM, but antitrust concerns are said to have undermined some important initiatives, including an effort to set toy company supply chain standards (1426).

In sum, the primary norm formation interactions represented at the conferences seemed to be business-to-business interactions. They drew on existing examples and past experiences, and were doubtless heavily influenced by the possibility of NGO 
attacks, but seemed to have taken a significant amount of the rule making process into business forums.

\section{Implementation}

The supply chains discussed at the conferences showed enormous variability. While some involved just a few suppliers of unique products to a single brand with a few retail outlets, others involved millions of suppliers going through dozens or hundreds of processors to dozens of different branded retailers. Interactions also necessarily reflected the different capacities of firms involved. Some supplier firms are large, complex, sophisticated corporations (for example in chemical supply chains), while others are small enterprises or individuals (for example in food supply chains). The nature of interactions with them therefore also varies greatly, although there were also several relatively typical types of interactions organized around lead firms.

Enrolling Procurers and Top Officials. A frequently mentioned type of interaction takes place inside the lead firm: between sustainability and procurement officers. Procurement officers are generally under structural pressure to minimize expenses, with immediate costs usually counting for more than longer term, somewhat uncertain risks. Sustainability officers are often in the position of advocating for criteria that can raise short term procurement costs. Hence, procurement officers often resist sustainability criteria. Numerous speakers mentioned the central importance of toplevel executive commitment to SSCM. Without it, sustainability will inevitably give ground to ever-present cost pressures. Sustainability advocates thus must gain strong commitments from executives and seek ways to institutionalize them $(1402,1407)$. This requires ongoing cultivation of executives, recruitment of new ones, and regular participation in high-level meetings so as to advocate for sustainability in specific decisions. One common strategy for institutionalizing sustainable purchasing is through promulgation of formal, publicly announced company policies of the kind described above (company purchasing policies and supplier codes of conduct). Another is to embed sustainability criteria in purchasing routines. A computer company executive, for example, described creating and implementing a new purchasing score card that includes numerous sustainability factors - environment, conflict minerals, and the like. Social and environmental scores can significantly raise or lower the scores of potential suppliers, thus advantaging sustainably run suppliers (1407).

Enrolling Suppliers. As discussed in more detail below, the conventional approach to ensuring supplier compliance with standards has been auditing, wherein buyers use auditors to ensure that suppliers are in fact meeting sustainability standards. While auditing is still very widely practiced, it has a number of limitations as discussed in the next subsection. Therefore, buyers have adopted a number of other interactive strategies to increase the likelihood of sustainability practices by suppliers.

Some companies have moved to shorten their supply chains and create direct relationships with suppliers, thus establishing relational governance schemes. One major food retailer, for example, buys as much as possible directly from farmers, 
believing that direct buying gives it more influence with suppliers and consequently increases compliance $(1407,1470)$. It also believes that standards are more likely to be adopted when the company presents them directly to suppliers, rather than commissioning brokers, auditors, or certifiers to do so. The same retailer has decided to use its own team to audit supplier practices, believing this strategy will be more successful because the team can decide what is really important, and can also demand that the supplier share information that it might refuse to share with a broker or auditor. The proposition that a lead firm might have greater success in selling standards was supported by another presenter, who explained that when his company started buying bananas directly from producers "guys on plantations said 'you've got to be joking', 'unions are ridiculous', etc. Eventually they got beyond that" (1420).

Many companies use external auditors but also seek to maintain direct relationships between sustainability staff and individuals within the supplying companies (e.g., 1407). The rationale is similar: to create internal advocates in the supplier for adherence to sustainability practices. A related argument is the idea of embedding sustainability, of institutionalizing it in the operating procedures of the company (1534). Interestingly, one major company represents a quite different approach to agricultural supply chain management. Olan International buys commodities from four million famers to supply branded giants like Nestle and Unilever. Thus, those corporations outsource the procurement and relationship function to a company that claims to specialize in relationships to farmers through a presence "at the farm gate," even for very small farmers (1524).

A third common prescription is to reward suppliers for achieving sustainability. Implicit in the relational governance strategy just discussed is the possibility of continuing trade with a committed customer, and this by itself can be a valuable protection against the vicissitudes of the open market (1420). Still, many suppliers participate in more than one supply chain or require significant financial or organizational investment to achieve sustainability standards. A number of companies give public awards to successful suppliers. One classifies them in levels - bronze, silver, and gold - that provide incentives for progress and recognize their achievements in making improvements (1430). Nonetheless, many participants argued that the additional costs of achieving sustainability require additional revenue (e.g., 1401, 1402), a so-called "green premium." Some countered that there is no need for a green premium, either because sustainable suppliers will thrive directly as a result of their improved operations (the so-called "business case for sustainability") or, somewhat tautologically, that there is no reason to pay a green premium to people who are simply doing what they are supposed to do anyway. There were few agreed solutions for this problem. One argument was that consumer education is urgent, because that is the only way to make sustainability pay. Another was that in some cases government action is necessary. In Bangladesh, for example, it is hard to sell sustainability to suppliers. Western buyers may want it, but fifty percent of the trade is with China, "which doesn't care at the moment" (1420). 
Capacity Building. An important feature of the widespread commitment to relational governance is its stress on capacity building. Given its potential to contribute to product quality and economic sustainability, capacity building receives a great deal of discussion and promotion, particularly with regard to marginal suppliers and small and medium enterprises. A common element of the prescription is that suppliers should be encouraged not simply to meet current standards, but to pursue continuous improvement (e.g., 1405, 1410, 1415, 1423, 1511, 1520). This, it is claimed, will instill innovation capacity and the ability to adapt to changing conditions. The underlying arguments have two interesting variants. One focuses on enhanced competitiveness and ability to thrive in a difficult market. The other focuses on more humane work conditions. It argues that the relatively low level of sustainable production in many developing countries is tied to mistreatment of workers. The solution to achieving better results is to "figure out how to turn disengaged, dissatisfied workers into engaged ones" (1421). The key to this, in turn, is to pay a living wage and allow freedom of association and collective bargaining, which are well correlated with a living wage $(1419,1421)$. Some speakers argued that it is necessary to get suppliers to see the benefits of increased capacity so they "will own it themselves" (1407), which can also be seen as an apparently benign governmentality strategy.

While the above are general prescriptions, one case description indicates the potential reach of the capacity building model. In describing the building of the Grancolombia Gold operation, the presenters told a story of taking on a legal gold concession in Colombia and dealing with staggering problems posed by thousands of illegal artisanal miners (they said 10,000) and 195 illegal mines. These included mercury pollution, child labor, prostitution, poverty, illegal gold sales, tax avoidance, and others. Grancolombia reacted not by evicting the miners, nor even by making them employees, but by taking them into their supply chain. They allowed artisanal miners into the first few levels of their industrial mine and also helped them legalize their claims on land outside the concession. They paid the artisanal miners the London spot price for their gold, instead of the much lower black market prices they had been receiving. In return they insisted on the ending of child labor, payment of taxes, contributions to the social security system - and apparently entry into the formal legal system generally. Thus, the capacity building model included facilitating movement into an institutional framework in which SSCM could plausibly function. The story is not a simple or unalterably happy one. For example, the presenters noted active ongoing strikes they said were provoked by narcotraficantes, who were losing out as a result of the legalizing economy. Moreover, the documentation is thin enough to counsel skepticism. Nonetheless, the example suggests the possible reach of capacity building beyond the boundaries of the firm to include public institutions more generally.

Collaboration. Perhaps the most common refrain among presenters was the importance of increased collaboration. The called-for collaboration can occur at any level, or among levels, and in any of the ANIMEE tasks. Within tiers, collaboration can occur in standard setting, auditing (discussed below), data sharing, etc. Such intra-tier collaboration, particularly, creates the kinds of antitrust questions noted in the agenda 
setting section. Presenters disagreed about the degree to which antitrust law is a problem, but they had all clearly thought about and worried about it. One who was quite comfortable with antitrust law claimed that it leaves a "tremendous amount of latitude to collaborate without getting too close," and that, while it can be constraining, the constraints are worth it. "It costs some money for lawyers, but it's a fair price to pay for not having cartels" (1403).

In the implementation process, collaboration occurs most often in the form of information sharing within tiers, usually about suppliers, as further discussed in the monitoring section below. Across tiers, it can take the form of capacity building discussed above or simply be a kind of joint problem solving regarding how to make a better product or make a product in a better way. As one presenter remarked: "it's simply about putting our challenges on the table and working them out together" (1410). Another pointed out that often even big buyers cannot sway suppliers based on power alone, since the suppliers usually have other buyers (1420). Hence again, collaboration is necessary to achieve joint gains.

Cross-sector collaboration was occasionally mentioned, but described as extremely difficult (1414). It is seen as desirable in two regards. First, it can provide helpful examples of practices in other sectors. Second, widespread sustainability collaboration may create enough of a bloc to help counter corruption in developing countries (1414). Overall, however, there does not appear to be much direct crosssector collaboration in SSCM. Indirectly, it mainly takes the form of shared learning through websites, practice guides (Leipzigger 2017), and episodic events such as the conferences reviewed here.

Managing Across Non-Contiguous Tiers. Much of the analysis thus far has focused on direct buyer-supplier relationships. Yet important challenges inhere in multi-tier supply chain management. The example of the computer companies forced to deal with tantalum, told above, involved suppliers several tiers upstream from the companies. The computer companies ended up organizing a meeting of the entire supply chain and eventually establishing a conflict-free smelter certification program that included a "bag and tag" program using radio-frequency identification (RFID) devices to follow the minerals from mine to smelter. They thereby averted a potential boycott that would have been unnecessarily detrimental to non-conflict producers (1416).

One of the computer company CSR managers opined that if they had done a human rights risk assessment beforehand, they "would not have thought of this," since it was such a small part of such a large and complex supply chain (1407). Given the complexity of many supply chains, and the effective impossibility of examining them exhaustively, the common prescription was to "cut through the complexity and figure out where the hotspots are" (1411). The CSR team can then focus on correcting problems in those processes before turning to others. One presenter also stressed that this is more difficult than it may seem, because investigating risks often "does not get rewarded" (1422). She argued that corporate culture change is necessary to reward such activity: companies "can't just hope to hell nothing will emerge." Another noted 
that the job is never ending, because suppliers constantly change, posing endless new challenges of finding and addressing hotspots (1402) - and presumably also for relational governance.

In sum, most success to date has occurred with tier one suppliers. Presenters agreed that knowledge of tiers three to five is usually quite murky. Investigation can lead into "people's back yards in developing countries" (1402). One solution would be to rely on actors in tiers adjacent to the tiers at issue, since they will usually garner the necessary knowledge most easily. However, this requires a degree of enrollment into the mission, resource commitment, and supply chain integration that is often absent. The more suppliers, the more buyers, and the more rapid change in the industry, the more complex is the problem. Hence, supply chain managers are thrown back on frequent audits of what can be a quickly changing cast of suppliers.

\section{Monitoring}

Monitoring can helpfully be divided into two forms with regard to SSCM: micro and macro. The micro one - "auditing" - is widespread, although not necessarily frequent in supply chain management. The macro one - systemic tracking of environmental and social effects of production practices - is rare, and is typically carried out by other actors, such as states, academic researchers, or large NGOs.

Auditing. Auditing is the practice of checking whether an actor is meeting applicable requirements or commitments. Typically, it involves taking a list of requirements and checking them against the subject firm's behavior or performance. Audits can be more or less intensive, but they have a tendency to take a standardized, bureaucratic form, perhaps in part to project an image of objectivity.

Presenters voiced several vigorous critiques. The first was simply that audits use up excessive resources. They involve a considerable amount of work for the auditing entity, and can be even more work for the supplier, which may be subject to multiple audits from many different buyers. A presenter estimated that an average Chinese factory producing for eight brands may have 20 audits per year, along with pressure to be faster, cheaper, more innovative, etc. (1431). The factory will necessarily devote considerable resources to dealing with audits, and may come to see them as a nuisance to be gotten around - an imposition by them on us (1505). The audits may be duplicative, in which case they may come to seem even more senseless, or they may be different in many small ways, in which case they impose additional costs of demonstrating compliance without necessarily producing useful information or improved operations. One response to this critique is that audits and reporting should be more standardized, and a fair bit of standardization seems to be occurring (1403, 1428,1532 ). A stronger response is that audits should also be shared: "an audit for one is an audit for all." The TfS chemical supply chain audit system does so. Fifteen companies carry out 200 audits per year, thus covering the supply network and significantly reducing costs (1402). According to the presenter, the joint audit process required considerable discussion and work with lawyers, but is working well. 
A second critique is that audits do not always produce useful information. This may be because the goals at issue are difficult to measure. For example, compliance with the minimum legal wage may not provide a living wage (1509). Or it may be because the audit, while covering all of the formal criteria, fails to deal adequately with intangible issues, such as worker morale, that require assessment (1403). The auditor may not be empowered to exercise the kind of judgment that is required. Additionally, professional auditors are often very hesitant to give advice on how better to comply with standards, although they may order "corrective actions" (1422). Like many government inspectors, they see such advice giving as posing conflicts of interest.

A third critique is that audits often simply do not work. One presenter said that at one time his company thought, based on audit results, that the vast majority of Chinese factories were compliant with fire safety laws. On closer inspection, however, they found that less than half were. One factory, according to the presenter, had five people on staff just to deal with auditors. His proposal, and evidently the strategy of his group, is to have people ("passionate people") actually work in the factories and live in the dorms (1512). The same speaker argued that audit resources are better invested in coaching and mentoring, since it is the weakest producers who need the most help. Speakers gave several other examples of audited workplaces that turned out to involve significant violations, including in developed countries. There was tacit acceptance that in many cases it may not be feasible for auditors to ferret out violations, since the audited companies control the situation and may be able to hide problems. Where the problems involve treatment of workers, as did most of the shared examples of undetected violations, a common suggestion is to focus on finding ways of empowering the workers. These methods might involve giving them language skills sufficient to defend themselves, helping them unionize, or setting up a call-in line where workers can anonymously report problems while not at work. Independent parties can then take those concerns to the companies. This last arrangement has reportedly been successful in both China (1431) and India (1432).

Finally, presenters made several other important points about auditing, all of which seem to suggest that SSCM auditing is likely to grow both more important and more contested in the near future. First, there is a university-affiliated consortium promoting life-cycle analysis as a scientific way of assessing supply chain sustainability. The group claims to provide a "scientific decision tree to identify major hotspots and universal improvement opportunities." It also claims over a hundred members and thousands of users, including the two thousand largest retailers, worldwide (1503). Second, a presenter asserted without any apparent dissent that environmental targets are easier to quantify and assess than are social ones, which are harder to monetize and subject greater debate (1405). Third, carbon accounting is making a major appearance in auditing protocols (1504). Finally, questions are being raised about control of data provided by producers. Among others, the farming community is reported to be asking about rights to control data and where it should be stored (1415). Beyond farmers' control, GPS data is also being used to monitor plantings of farmers, annual growth, and the like (1508). 
Transparency. Increased transparency has been touted for decades as a way of almost automatically enhancing social and environmental performance, because both the actor and others can "see" the level of performance and take action as a result. Rapidly improving information management systems make this strategy particularly appealing in supply chain management. Retailers have long been able to use SKU codes to track merchandise back to specific suppliers, and potentially to discipline them for shoddy production. Now, QR codes and other technologies make it possible for many actors along supply chains to see desirable information. Edible OR codes, for example, are starting to become common on products like sushi (1401), creating the possibility of supply chain governance interactions with interested consumers.

Such strategies are not always possible, particularly for components that will be transformed in the manufacturing process, as in the tantalum case. Still, transparency can also be achieved simply by making privately held information public. For example, the metal smelter could list its ore suppliers and the fabricator could list its smelter sources, as Intel partly did by naming its top 100 suppliers in its most recent CSR report (Intel 2017-18), However, this is rarely done. More commonly, corporations resist sharing supplier information for competitive reasons. A number of speakers were prepared to share certain information, for example the results of supplier audits within industry groups, but few indicated willingness to share with the public as a whole. Indeed, some speakers and participants at the conference expressed great hesitancy about making public announcements of SSCM activities. When I inquired why, I was told that it often seems "unwise to "stick your head above the parapet" (1535). No matter how careful a company may be in sourcing products, an enterprising reporter or NGO may still be able to run an exposé demonstrating failed claims and portraying the company as deceitful.

\section{Enforcement}

As suggested above, there is good reason to believe that rates of non-compliance with sustainability standards are often high, including in audited firms (1421). Presentations by sustainability professionals rarely referred to enforcement as such. Instead, they tended to emphasize increasing engagement, mentoring, capacity building, and the like. Auditors commonly list corrective actions, which then can be checked in the future. If these methods fail, and the noncompliance is serious enough, buyers have the option of dropping noncompliant suppliers, provided they are replaceable. In many situations, however, buyers' enforcement powers are limited by their relative market power and the availability of alternative suppliers. Moreover, dropping a supplier may do nothing to improve performance, since the supplier simply leaves the network and probably sells to less discriminating buyers. Thus, buyers often are inclined either to let the violations pass, or to find a cooperative way of addressing them.

Other possible enforcers include civil society organizations, worker organizations, consumers, and governments. Host governments have formal jurisdiction over suppliers, and many violations of supplier codes are also violations of state laws. However, host state governments and their legal systems often are very 
unreliable enforcers. As one speaker emphasized, developing countries typically want to increase their comparative advantage so as to be successful exporters, and one easy way to do this is to reduce formal and informal worker and environmental protections (1420). A number of speakers expressed a desire for better host state regulation, because it can reduce overall enforcement costs (companies do not have to do it themselves), establish uniform standards, and generally create a more predictable business environment. However, there seems to be little sign of this happening. The appeal of lax standards to minimize costs and increase comparative advantage is strong in many places, as are the attractions of bribes for special treatment. Some recent trade agreements, such as the Trans-Pacific Partnership Agreement create a duty to enforce, but many years and much agitation will probably be required for such provisions to have significant effect (Meidinger 2018).

In some cases, the promise of activating civil society organizations or workers' organizations may be greater than the hope of increased state enforcement. However, many developing country governments strictly control protest actions, allowing them only when they suit government interests, which will often not be the case when supplier profits are threatened.

Consumer whistle blowers, finally, may be effective in some cases. However, often their only method is a consumer boycott, and that is a very blunt instrument. It is often difficult to boycott only the products of 'bad' suppliers, and even if it is possible, the boycott may leave workers worse off (perhaps unemployed) than they would have been in their substandard work situations.

In sum, the enforcement system for SSCM is a spotty composite of relatively weak links. This may mean that the capacity of SSCM to actually achieve any significant goals is severely limited. Differently viewed, it will have to rely on the aggregated, individually calibrated actions of many different enforcers, who often must rely on limited information. Accordingly, the role of enforcement as traditionally understood (the application of rules backed by sanctions) seems unlikely to play an important role in SSCM for some time to come.

\section{Evaluation and Reform}

There is no overarching mechanism for evaluating or reforming SSCM, although there is a rapidly growing flow of information. An increasing number of corporations are issuing reports on their sustainability activities, including supply chain management, sometimes under UN Global Reporting Initiative (GRI) guidelines and sometimes simply on their own. But the amount of useful SSCM information they contain tends to be quite limited. They generally provide very little detail on the structure or participants in their supply chains, typically for competitiveness reasons. Although some mention improvements in the performance of their supply chains, they very rarely detail the nature of the improvements, and almost never describe the degree of remaining problems. Thus, corporate responsibility reports rarely contain meaningful measures of effectiveness. This could change somewhat if GRI or OECD requirements (OECD 2018) become more demanding, or perhaps even if the state of 
the art improves greatly. Thus far, there is not much reason for optimism on either count.

Meanwhile, much of the broad evaluation and reform activity that exists takes place in forums like the conferences discussed in this paper. Those assessments are generally anecdotal and unsystematic. Outside the conferences, there appears to be a growing body of academic research on SSCM, its effectiveness, and possible improvements. However, that research was not mentioned by the SSCM professionals, and the conferences were nearly devoid of academics. It thus appears that catalyzing an effective evaluation and reform function will require systematically connecting academic researchers to professional supply chain managers. While such connections may be developing in the business and human rights arena, it will take some time for meaningful networks of research and dialogue to generate information and analysis capable of supporting broad conclusions about the performance of SSCM.

\section{Conclusion}

This article applies the TBGI framework to the management practices described by SSCM professionals in the hope that the framework will help to better understand supply chain governance interactions, and thereby help with assessing the governance value of the SSCM movement. This section offers some reflections about the usefulness of the framework and the role of SSCM in improving governance capacity, ratcheting up standards, and empowering marginalized interests.

\section{The TBGI Framework}

The TBGI framework has proved moderately useful in sorting through the blooming, buzzing confusion of the SSCM world. It helps both to broaden the research gaze and to focus it on particular types of activity. However, it also suffers from certain limitations in portraying the governance interactions in SSCM. The first is that its four categories of interaction are considerably more limited than the patterns described by the presenters. They recounted a wide variety of networked coordination behaviors, some mixed with cooptation or competition, or both. Moreover, some kinds of interactions, such as information sharing and institutional mimicry do not seem to fit well into any of the categories. More generally, many of the interactions discussed seem better described as relationships. Their importance was in creating continuity, and many interactions were aimed at institutionalizing desirable practices and relationships. These observations raise the question of whether the concept of interactions should be refined to distinguish episodic and institutionalized variants.

A second question arises from the relative indifference of the TBGI framework to the SSRM goals of supply chain dynamism, innovation, and capacity building. This was particularly apparent in the limitations of the "enforcement" category for comprehending the many forms of coaching, cajoling, modeling, information sharing, and mentoring that seem to characterize much SSCM interaction aimed at changing supplier behavior. This limitation may reflect the implicit public law and political science-based roots of the regulatory categories, which seem to assume a state-like 
"other" that promulgates, enforces, and evaluates rules. The SSCM example may call for revisions to accommodate a more interpenetrated system of governance interactions.

Finally, this article seeks to describe the interactive strategies of SSCM managers and to stay at that level of interaction. In doing so, however, it may also understate the importance of the received body of SSCM discourse, discursive moves on the part of the actors, and the general role of ideas. It seemed clear that many of the presenters were focused on articulating powerful ideas, and believed that doing so was an important way of advancing governance. If there is a lesson here, it may be that it will often be helpful for TBGI researchers to work at more than one level of interaction.

\section{Improving Governance Capacity?}

While the TBGI framework may be helpful in describing SSCM interactions on a purely empirical basis, an important purpose of doing governance research is to find out whether it is actually helping, and if so how. For this volume, we have framed the first question as whether SSCM interactions contribute to improving governance capacity. At a basic level, the answer would seem to be "yes." Clearly, it should be helpful to sustainability governance to conscript the previously unutilized supply chain management capacities of powerful businesses, and for them to institutionalize sustainability practices. It is much harder to say, though, just how helpful. At present, we have little information on what proportion of transnational supply chains are covered, or are likely to be within a reasonable time, or how effective SSCM strategies actually are. This especially so because of the extreme shortage of information on actual enforcement ations by lead firms.

It is thus natural to be skeptical. And yet, a number of factors may bolster and accelerate the growth of SSCM. Important sources of capital, most recently the $\$ 6$ trillion investment fund, BlackRock, are increasingly pressuring businesses in which they invest to demonstrate social responsibility or risk losing capital (Sorkin 2018). Regional trade agreements like the TransPacific Partnership would also mandate state encouragement of corporate responsibility programs. Risks of domestic legal liability for the actions of supply chain partners are also growing (e.g., Kinley and Navidi 201314).

Yet still, there remain grounds for serious skepticism. Capital only flows and businesses only succeed when there are profits, and profit requires constraining costs. Moreover, many of the lead firms pushing SSCM have near-monopsony power and relatively limited political accountability. The degree to which their behavior can be reliably shaped by the power of norms over that of profits must remain subject to serious question. And finally, many of the goals of institutionalizing SSCM can also be seen as a kind of governmentality strategy - getting the governed to think the idea is their own and govern themselves accordingly without having true agency. It thus becomes more questionable whether this is a true improvement in governance capacity. There was little in the presentations 


\section{Ratcheting Up Standards?}

SSCM contains a significant commitment to continual improvement (ratcheting), and many of the presenters discussed ways of promoting and rewarding it. However, that improvement is centered primarily on business goals, mainly productivity and adaptability. It is also constrained by the profit requirements noted above. Together, these requirements may place invisible upper limits on social and environmental standards.

Regardless of how far ratcheting might go in terms of protecting workers, communities, and the environment, it is important to stress that the SSCM concept of ratcheting seems to envision a change in the very nature of standards - away from specific outputs and toward greater organizational capacity for adaptation and innovation. Thus, it may be focused more on the characteristics of the organization, than on the nature of its activities.

It remains possible, of course, that environmental and social standards will become more stringent as supply chain participants become more nimble and innovative, but the narratives examined in this paper provide a limited basis at best for such a conclusion. Moreover, the dispersal of standard setting to so many diverse actors will make it difficult to discern how much ratcheting up actually occurs. Standards may be strict in some areas and weak in others, absent the "super-aligner" called for by some of the presenters.

\section{Empowering Marginalized Interests?}

The primary form of "empowerment" in SSCM is through rules. Rules are used to define protections for workers, communities, and the environment. Thus, much of what might be thought of empowerment is top-down and takes the form of protection by more powerful actors. It occurs mainly through codes that already specify the legitimate expectations of the protected interests. The moving oar has been largely in the hands of lead firms. Several SSCM practitioners did describe programs in which firms empower workers by giving them voice through hotlines, unions, and other arrangements. Overall, however, worker empowerment still seems to be a relatively small part of the SSCM repertoire. The majority of presentations focused on effectuating more control by lead firms to get suppliers to follow practices protecting people and nature in a predictable manner. As long as that focus holds, empowerment of marginalized interests in SSCM seems likely to remain limited. 


\section{REFERENCES}

Becker, Howard S. 'Field Work Evidence' in Sociological Work: Method and Substance (Chicago, Aldine 1970)

Better Coal [2017] 'Who we are' <https://bettercoal.org/who-we-are/> accessed 19 June 2018

Better Coal [2011] 'Anti-Trust Compliance Policy Statement - Principles' $<$ https://bettercoal.org/wp-content/uploads/2018/04/Bettercoal-Anti-trust-Policy1.pdf $>$ accessed 19 June 2018

BSR [2018] Business for Social Responsibility, 'About Us' <http://www.bsr.org/en/about>accessed 19 June 2018

Christopher, Martin, Logistics \& Supply Chain Management (4th edn, Prentice Hall 2011)

Conroy, Michael, Branded! How the 'Certification Revolution' is Transforming Global Corporations (New Society Publishers 2007)

Dodd-Frank Wall Street Reform and Consumer Protection Act, Pub. L. No. 111-203, \$ 929-Z, 124 Stat. 1376,1871 (2010) (codified at 15 U.S.C. \$ 780 )

Eberlein Burkard, Kenneth W. Abbott, Julia Black, Errol Meidinger and Stepan Wood, 'Transnational Business Governance Interactions: Conceptualization and Framework for Analysis' [2014] 8 Regulation and Governance 1, 1-21

Ecovadis (2018) <http://www.ecovadis.com/us/about-ecovadis/> accessed 19 June 2018

Ethical Corporation (2018) <http://www.ethicalcorp.com> accessed 19 June 2018

Ethical Trading Initiative (2018a) 'ETI's origins' <http://www.ethicaltrade.org/abouteti/why-we-exist/etis-origins $>$ accessed

Ethical Trading Initiative (2018b) 'ETI base code' <http://www.ethicaltrade.org/eti-basecode> accessed 19 June 2018

French Duty of Vigilance Law of 2017, L. n 2017-399, 27 March 2017 relative au devoir de vigilance des sociétés mères et des entreprises donneuses d'ordre: JO 28 March 2017, texte $n^{\circ} 1$ 
International Trade Center (ITC 2018), 'Standards Map: Your Roadmap to Sustainable Trade', at <http://www.standardsmap.org/identify $>$ accessed 19 June 2018

Gereffi, Gary "Global Value Chains and International Competition," Antitrust Bulletin, 56(1): 37-64 (2011)

Gereffi and Lee, 'Why the World Suddenly Cares About Supply Chains,' Journal of Supply Chain Management, 48(3):24-32 (2012)

Intel (2017-18) "Corporate Responsibility at Intel" $<$ http://csrreportbuilder.intel.com/PDFfiles/CSR-2017_Full-Report.pdf> accessed 19 June 2018

Jenkins, Rhys 'Corporate Codes of Conduct: Self-Regulation in a Global Economy', UN Research Institute for Social Development, Technology, Business and Society Program Paper Number 2 (April 2001) $<$ https://www.researchgate.net/profile/Rhys Jenkins2/publication/37150822 Code s of Conduct Self Regulation in a Global Economy/links/5448 $\mathrm{d}_{2} \mathrm{f}_{30 \mathrm{of}} \mathrm{f}_{14} \mathrm{fb}_{\mathrm{f}} \mathrm{1}$ 44837.pdf> accessed 19 June 2018

Kent, John L. Jr. and Daniel J. Flint, 'Perspectives on the Evolution of Logistics Thought' [1997] 18 Journal of Business Logistics 2, 15-29

Kinley, David and Jahan Navidi, "The Long Arm of Human Rights Risk: Supply Chain Management and Legal Responsibility," The Business and Human Rights Review (3) 2013-14

KPMG 'The Road Ahead: The KPMG Survey of Corporate Responsibility Reporting 2017' $<$ https://assets.kpmg.com/content/dam/kpmg/xx/pdf/2017/10/kpmg-survey-ofcorporate-responsibility-reporting-2017.pdf > accessed 19 June 2018

Langlois, Michelle, "Human Rights Reporting: Are Companies Telling Investors What they Need to Know?", Shift, New York, May 2017. $<$ https://www.shiftproject.org/media/resources/docs/Shift MaturityofHumanRight sReporting_May2017.pdf>accessed 19 June 2018

Leipziger, Deborah, The Corporate Responsibility Code Book, Routledge, 2017

Marchi, V. D., Maria, E. D. and Micelli, S. (2013), Environmental Strategies, Upgrading and Competitive Advantage in Global Value Chains. Business Strategy and the Environment 22: 62-72. 
McCarter, Mathhew W. and Gregory B. Northcraft, 'Happy together? Insights and implications of viewing managed supply chains as a social dilemma' [2007] 25 Journal of Operations Management 498-511

Meidinger, Errol 'The Administrative Law of Global Private-Public Regulation' [2006] 17 European Journal of International Law 47-87

Meidinger, Errol (2008), "Multi-Interest Self-Governance through Global Product Certification Programs." In Olaf Dilling, Martin Herberg, and Gerd Winter, editors, Responsible Business? Self-Governance in Transnational Economic Transactions.

Oxford: Hart Publishing (pages 259-291)

Meidinger, Errol (2018), 'The TPP and Environmental Regulation,' Forthcoming in Benedict Kingsbury, et al, Megaregulation Contested: Global Economic Ordering after TPP. Oxford University Press.

Porter, Michael T. Competitive Advantage (The Free Press 1985)

OECD (2018) OECD Due Diligence Guidance for Responsible Business Conduct http://mneguidelines.oecd.org/OECD-Due-Diligence-Guidance-for-ResponsibleBusiness-Conduct.pdf

Seuring, Stefan and Martin Müller, 'From a Literature Review to a Conceptual Framework for Sustainable Supply chain management,' Journal of Cleaner Production, 16: 1699-1710 (2008)

Sorkin, Andrew Ross, "BlackRock's Message: Contribute to Society, or Risk Losing Our Support, New York Times, Dealbook, January 15, 2018

Together for Sustainability (TFS 2018) 'About Us' http://www.tfsinitiative.com/about us.html> accessed 19 June 2018

UK Government (2015) 'Modern Slavery Act' $<$ http://www.legislation.gov.uk/ukpga/2015/30/contents/enacted/data.htm> accessed 19 June 2018

United Nations (2011) Guiding Principles for the Implementation of the United Nations 'Protect, Respect and Remedy' Framework, A/HRC/

United Nations Global Reporting Initiative (GRI) (2015) $<$ https://www.globalreporting.org/resourcelibrary/GRIG4-Part1-ReportingPrinciples-and-Standard-Disclosures.pdf > accessed 19 June 2018 
United Nations 'Sustainable Development Goals: 17 Goals to Trannsform the World <http://www.un.org/sustainabledevelopment/sustainable-development-goals/> accessed 19 June 2018

Unilever (2018) 'Responsible Sourcing Policy' <https://www.unilever.com/Images/slpunilever-responsible-sourcing-policy-2014_tcm244-409819_en.pdf $>$ accessed 19 June 2018

'HP Supplier SER Requirements' <http://www8.hp.com/us/en/hp-information/globalcitizenship/society/supplier-ser-requirements.html> accessed 19 June 2018

van der Vorst, Jack G.A.J., Carlos A. da Silva, and Jacques H. Trienekens, 'Agroindustrial Supply Chain Management: Concepts and Applications' [2007] Agricultural Management, Marketing and Finance Occasional Paper 17, Food and Agriculture Organization of the United Nations, Rome, 2007, p. 15. $<$ http://www.fao.org/3/a-a136ge.pdf, accessed 19 June 2018. Figure used with permission.

Waters, Donald, Supply Chain Risk Management: Vulnerability and Resilience in Logistics (KoganPage 2011) 